\title{
Expression and contribution of the HIF-1 $\alpha$ /VEGF signaling pathway to luteal development and function in pregnant rats
}

\author{
LIXIANG WU ${ }^{1,2}$, ZHENGHONG ZHANG ${ }^{1}$, XIAOYAN PAN $^{3}$ and ZHENGCHAO WANG ${ }^{1}$ \\ ${ }^{1}$ Provincial Key Laboratory for Developmental Biology and Neurosciences, College of Life Sciences, \\ Fujian Normal University, Fuzhou, Fujian $350108 ;{ }^{2}$ Department of Pathophysiology, \\ Maternal and Child Health Hospital of Fujian, Fuzhou, Fujian 350001; \\ ${ }^{3}$ Department of Histology and Embryology, Jilin Medical College, Jilin, Jilin 132013, P.R. China
}

Received November 13, 2014; Accepted August 4, 2015

DOI: $10.3892 / \mathrm{mmr} .2015 .4268$

\begin{abstract}
Vascular endothelial growth factor (VEGF) is vital in normal and abnormal angiogenesis in the ovary, particularly during the early development of the corpus luteum in the ovary. However, the molecular regulation of the expression VEGF during luteal development in vivo remains to be fully elucidated. As the expression of VEGF is mediated by hypoxia-inducible factor (HIF)-1 $\alpha$ in luteal cells cultured in vitro, determined in our previous study, the present study was performed to confirm the hypothesis that HIF-1 $\alpha$ is induced and then regulates the expression of VEGF and VEGF-dependent luteal development/function in vivo. This was investigated using a pregnant rat model treated with a small-molecule inhibitor of HIF-1 $\alpha$, echinomycin (Ech). The development of the corpus luteum in the pregnant rat ovary was identified via performing assays of the serum progesterone, testosterone and estradiol concentrations by radioimmunoassay, accompanied with determination of the changes in the expression levels of HIF-1 $\alpha$ and VEGF by reverse transcription-quantitative polymerase chain reaction at different days of the developmental process. On day 5, serum progesterone levels were markedly increased, whereas serum levels of testosterone and estradiol did not change significantly. On day 17, the highest level of serum progesterone was observed, however, this was not the case for testosterone and estradiol. Further analysis of the expression levels of HIF-1 $\alpha$ and VEGF revealed that their changes were consistent with the changes in serum levels of progesterone, which occurred in the development of the corpus luteum in the ovaries of pregnant rats. Further investigation demonstrated that Ech inhibited luteal development through inhibiting the expression of VEGF,
\end{abstract}

Correspondence to: Dr Zhengchao Wang, Provincial Key Laboratory for Developmental Biology and Neurosciences, College of Life Sciences, Fujian Normal University, 8 Shangsan Road, Fuzhou, Fujian 350108, P.R. China

E-mail: zcwang@fjnu.edu.cn

Key words: hypoxia-inducible factor-1 $\alpha$, vascular endothelial growth factor, echinomycin, progesterone, corpus luteum mediated by HIF-1 $\alpha$, and subsequent luteal function, which was determined by detecting changes in serum progesterone on days 8 and 14. Taken together, these results demonstrated that HIF-1 $\alpha$-mediated expression of VEGF may be one of the important mechanisms regulating ovarian luteal development in mammals in vivo, which may provide novel strategies in treatment for fertility control and for certain types of ovarian dysfunction, including polycystic ovarian syndrome, ovarian hyperstimulation syndrome and ovarian neoplasia.

\section{Introduction}

The corpus luteum is a temporary endocrine structure in mammals, which is important in the female reproductive cycle and is formed temporarily from a ruptured and ovulated follicle with rapid angiogenesis (1-5). The ruptured follicle, which occurs immediately following ovulation is considered to be under hypoxia conditions due to bleeding and immature vasculature (6). Previous studies have indicated that hypoxia is important for establishing the vascular system during luteal development (5), which induces the expression of hypoxia-inducible factor (HIF)-1 $\alpha$ in luteal cells (7-11). When vascular endothelial factor (VEGF) is regulated by hypoxia, there is an upregulation of specific transcription factors, notably HIF-1 $\alpha(7,8,12)$. However, the physical role of HIF-1 $\alpha$ in this process of luteal development remains to be fully elucidated.

Notably, VEGF is important in the regulation of normal and abnormal angiogenesis in the ovary $(3,4,13-18)$, particularly in the newly formed corpus luteum (19-22). Hypoxia is a potent stimulus for the expression of VEGF $(14,23)$, as ovulation causes a decline of local oxygen concentration, producing a hypoxic environment, and may be the predominant stimulator for VEGF production in the developing corpus luteum $(5,24)$. However, there have been no reports regarding the contribution of HIF-1 $\alpha$ signaling to VEGF-dependent angiogenesis and luteal function during ovarian luteal formation in vivo.

Due to the important role of HIF-1 $\alpha$ in regulating the expression of VEGF in luteal cells cultured in vitro $(9,25)$, the present study hypothesized that the HIF-1 $\alpha$ signaling pathway contributes to VEGF-dependent angiogenesis and the following functions of corpus luteum in the ovary in vivo. 
Therefore, the present study investigated the expression levels of HIF- $1 \alpha$ and VEGF during luteal development in pregnant rats, determined by measuring serum hormone levels during luteal development. In addition, the effects of the HIF-1a small-molecule inhibitor echinomycin (Ech) on luteal function and HIF-1 $\alpha$-mediated expression of VEGF in the early corpus luteum of pregnant rats was investigated. The present study aimed to demonstrate that HIF-1 $\alpha$ is an important mediator of luteal functions in vivo, which may be an important mechanism regulating VEGF-dependent angiogenesis during luteal development in mammals.

\section{Materials and methods}

Animals. A total of 78 female Sprague-Dawley (SD) rats (body weight, 50-70 g; age, 25 days), and 21 male SD rats (age, 2-3 months) Wushi Experimental Animal Supply Co., Ltd. (Fuzhou, China). The animals were maintained under a $14 \mathrm{~h}$ light $/ 10 \mathrm{~h}$ dark schedule at $20-25^{\circ} \mathrm{C}$, with a continuous supply of chow and water. The study was approved by the Ethics Committee on Animal Experimentation of the Fujian Normal University (Fuzhou, China). All efforts were made to minimize animal discomfort and to reduce the number of animals used.

Experimental design. The rats were allowed to accommodate for 1-2 weeks prior to mating with males, which occurred at 2-3 months of age (179-250 g body weight). Previously unmated female rats (three per cage) were mated with an unvasectomized male (one per cage) and were examined every morning for the presence of a vaginal plug. Day 2 of pregnancy was defined as the day at which a vaginal plug was recovered. The pregnant females were removed and used in the subsequent experiments.

To further confirm the pregnant rat model, measurements of the serum levels of progesterone, testosterone and estradiol in the animals were measured on days 2, 5, 8, 11, 14, 17 and 20 of pregnancy. The rats were anesthetized with atropine (Sigma-Aldrich, St. Louis, MO, USA) on the days of sample collection prior to opening of the abdomen, and $\geq 3.0 \mathrm{ml}$ blood was collected from the abdominal aorta, and centrifuged at $1,000 \times \mathrm{g}$ at $4^{\circ} \mathrm{C}$ for $10 \mathrm{~min}$. The ovaries were rapidly excised and chilled in ice-cold $0.154 \mathrm{M} \mathrm{NaCl}$ with $14.0 \mu \mathrm{M}$ indomethacin (Sigma-Aldrich) immediately following perfusion for measuring the expression levels of HIF-1 $\alpha$ and VEGF.

For estimating the possible role of HIF-1 $\alpha$ /VEGF signaling during the formation of the corpora lutea in the pregnant rats, $1 \mathrm{mg} / \mathrm{kg}$ body weight Ech (BioViotic, Dransfelg, Germany), a small-molecule inhibitor of HIF-1 $\alpha$, was intraperitoneally injected on day 1 of pregnancy. DMSO (dimethyl sulphoxide; Sigma-Aldrich) served as a the control/vehicle. The plasma levels of progesterone and the expression levels of HIF-1 $\alpha$ and VEGF in the perfused ovaries were then determined on days 2, 8 and 14 .

For histological analysis, one ovary from each rat was fixed in $4 \%$ paraformaldehyde (Sigma-Aldrich), and the other ovary was snap-frozen and used for the remaining experiments.

Ovarian perfusion. To avoid the effects of the vascular system, ovarian perfusion was performed prior to collection of the ovaries. The female rats were perfused in vivo through the abdominal aorta with $0.154 \mathrm{M} \mathrm{NaCl}$. The animals were anesthetized with $0.05 \mathrm{mg}$ atropine $/ \mathrm{kg}$ body weight subcutaneously, $2.5 \mathrm{mg}$ diazepam/kg body weight intraperitoneally. (Sigma-Aldrich). The abdomen was opened via a mid-ventral incision and an intravenous cannula (1.4 mm outer diameter) was inserted via the aortic bifurcation. The abdominal aorta was clamped caudally to the celiac artery, and the inferior vena cava was severed. Subsequently, $40 \mu \mathrm{l}$ of the perfusion solution was perfused at ambient temperature through the lower abdominal vascular system for $\sim 5 \mathrm{~min}$ at constant pressure using a hand-held syringe. Perfusion was discontinued when the ovaries, particularly the corpora lutea, had become completely pale. The ovaries were then rapidly removed for subsequent analysis of gene expression.

Radioimmunoassay of the levels of progesterone, testosterone and estradiol. The levels of serum progesterone, testosterone and estradiol were determined using specific radioimmunoassay kits, according to the manufacturer's instructions. The progesterone RIA kit [intra-assay coefficient of variation (cv) $<4.3 \%$; inter-assay cv $<7.1 \%$ ], testosterone RIA kit (intra-assay $\mathrm{cv}<5.0 \%$; inter-assay cv $<10.0 \%)$ and estradiol RIA kit (intra-assay $\mathrm{cv}<3.5 \%$; inter-assay $\mathrm{cv}<7.0 \%$ ) were purchased from Atomic Gaoke Co., Ltd., Department of Isotope, China Institute of Atomic Energy (Beijing, China). Protein concentrations were determined using a Bio-Rad protein assay (Bio-Rad Laboratories, Inc., Hercules, CA, USA), with bovine serum albumin standards.

$R N A$ extraction and reverse transcription-quantitative polymerase chain reaction (RT-qPCR) analysis of the $m R N A$ levels of VEGF and HIF-l $\alpha$. Total RNA was extracted from the ovaries using TRIzol solution (Invitrogen Life Technologies, Carlsbad,CA,USA) and then reverse-transcribed using a cDNA Synthesis kit; Bio-Rad, Laboratories, Inc.). The reverse-transcribed products were amplified using a TaqMan Gene Expression Assay kit (Applied Biosystems Life Technologies, Foster City, CA, USA), with TaqMan Universal PCR Master Mix (4304437), HIF-1 $\alpha$ primer (Rn00577560_m1) and VEGF primer (cat. no. Rn01511601_m1). A kit for detecting the levels of 18S ribosomal RNA (Hs99999901_s1) was used as an endogenous control. The $20 \mu$ l PCR reaction mix contained $10.0 \mu 1$ 2X TaqMan Gen Expression mix (Applied Biosystems Life Technologies), 1.0 ul 20X TaqMan Gene Expression Assay (Applied Biosystems Life Technologies), $4.0 \mu \mathrm{l} \mathrm{cDNA}$ template and 5.0 $\mu \mathrm{l}$ RNase-free water. The PCR conditions of the RT-qPCR system (Applied Biosystems Life Technologies), were as follows: $50^{\circ} \mathrm{C}$ for $2 \mathrm{~min}, 95^{\circ} \mathrm{C}$ for $10 \mathrm{~min}$, followed by 40 cycles at $95^{\circ} \mathrm{C}$ for $15 \mathrm{~s}$, and $60^{\circ} \mathrm{C}$ for $1 \mathrm{~min}$. The relative gene expression levels were calculated in accordance with the ${ }_{\Delta \Delta \mathrm{Ct}}$ method (26-29). Relative mRNA levels were expressed as $2^{-\Delta \Delta C t}$ values (26-29).

Western blot analysis of the protein expression levels of VEGF and HIF- $1 \alpha$. The protein samples were obtained using a Nuclear and Cytoplasmic Protein Extraction kit (Beyotime Institute of Biotechnology, Haimen, China). Protein concentrations were determined using a Bio-Rad assay with bovine serum albumin standards. Following determination, $20 \mu \mathrm{g}$ of the protein 
samples were subjected to $8 \%$ SDS-PAGE gel electrophoresis and then electrophoretically transferred onto a polyvinylidene difluoride membrane (Pall Life Sciences, Port Washington, NY, USA). The membrane was washed with phosphate-buffered saline with $0.2 \%$ Tween 20 (PBST; Sigma-Aldrich), blocked with $5 \%$ non-fat dried milk in PBST, and probed with mouse monoclonal anti-HIF-1 $\alpha$ (1:500; cat. no. ab1; Abcam, Cambridge, MA, USA) and rabbit polyclonal anti- $\beta$-actin (1:5000; cat. no. NB600501H; Novus Biologicals, Littleton, $\mathrm{CO}$, USA) primary antibodies overnight at $4^{\circ} \mathrm{C}$. Following washing, the membranes were incubated with horseradish peroxidase-conjugated goat anti-mouse immunoglobulin (Ig)G (1:5,000; cat. no. NB7570; Novus Biologicals) or goat anti rabbit IgG (1:5,000; cat. no. NBP230348H; Novus Biologicals) secondary antibodies for $1 \mathrm{~h}$ at room temperature. $\beta$-actin was used as a loading control. To detect the immunoblotting signal, $2 \mathrm{ml}$ enhanced chemiluminescence detection solution was used (Thermo Fisher Scientific, Inc., Rockford, IL, USA) , and the membrane was exposed to Kodak OMAT film (Kodak, Rochester, NY, USA). The blots were quantified using ImageJ 1.49 software (National Institutes of Health, Bethesda, MD, USA).

Statistical analysis. Data are presented as the mean \pm standard error of the mean. The significance of differences in the mean values within and between multiple groups were evaluated using one-way analysis of variance, followed by Tukey's multiple range test. Statistical analysis was conducted using Sigmastat 3.02 (Sigma-Aldrich). $\mathrm{P}<0.05$ was considered to indicate a statistically significant difference.

\section{Results}

Changes in the levels of serum progesterone, testosterone and estradiol during luteal development in pregnant rats. In order to confirm successful generation of a rat model of pregnancy in the present study, the levels of serum progesterone, testosterone and estradiol were examined during luteal development. The results demonstrated that serum progesterone concentration was significantly increased on day 5 ( $\mathrm{P}<0.05$; Fig. 1A), however, no significant change was observed in the remaining two hormones (Fig. 1B and C), suggesting that the corpus luteum had already formed. The level of serum progesterone was highest on day 17 ( $\mathrm{P}<0.05$; Fig. 1A), indicating that the corpus luteum had matured. A decrease of serum progesterone was observed $(\mathrm{P}<0.05$; Fig. 1A) and suggested luteolysis had occurred. At the same time, serum estradiol concentrations increased significantly (Fig. 1B) and stimulated follicular development during the subsequent follicular wave in the ovary.

Changes in the mRNA levels of VEGF and HIF-la during luteal development in pregnant rats. To investigate the possible role of the HIF-1 $\alpha /$ VEGF signaling pathway during the development of the corpus luteum in pregnant rats, the present study also detected the mRNA expression levels of VEGF and HIF-1 $\alpha$ in the ovaries during luteal development. The mRNA expression level of VEGF increased significantly between days 5 and 17 (Fig. 2A), and then decreased markedly on day 20 (Fig. 2A). Notably, the changes in the mRNA expression levels of HIF-1 $\alpha$ were similar to those of VEGF
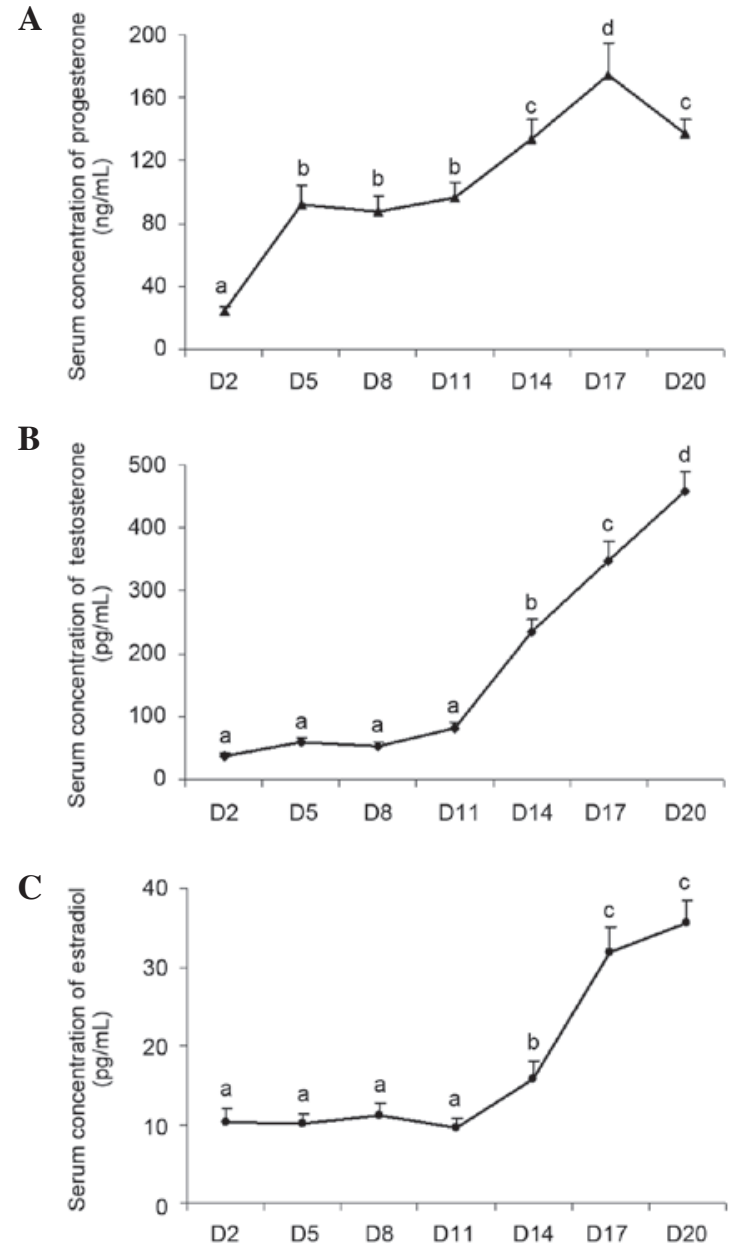

Figure 1. Changes in the serum levels of progesterone, testosterone and estradiol during luteal development in pregnant rats Adult female rats were mated with males to induce pregnancy. Day 1 of pregnancy was defined as the day when a vaginal plug was recovered. Animals were sacrificed by decapitation and trunk blood was collected for hormone determination on days 2 , $5,8,14,17$ and 20. The serum levels of (A) progesterone, (B) testosterone and $(\mathrm{C})$ estradiol were examined. The abdomen was opened, and the ovaries were rapidly excised and chilled in ice-cold $\mathrm{NaCl}(0.154 \mathrm{M})$ with $14.0 \mu \mathrm{M}$ indomethacin immediately following perfusion to determine the expression of HIF-1 and VEGF. Data are presented as the mean \pm standard error of the mean. The different letters indicate statistically significant differences in the mean values within and between multiple groups, which was evaluated using a one-way analysis of variance, followed by Tukey's multiple range test. $\mathrm{P}<0.05$ was considered to indicate a statistically significant difference. VEGF, vascular endothelial growth factor; HIF, hypoxia-inducible factor; D, day of pregnancy.

(Fig. 2B), indicating that the HIF-1 $\alpha /$ VEGF signaling pathway may be involved in luteal development and the following endocrine function.

Effects of Ech on luteal development in pregnant rats. In order to further clarify the involvement of HIF-1 $\alpha$ in luteal development, the pregnant rats were injected with Ech, a small-molecule inhibitor of HIF-1 $\alpha$, on day 2 of pregnancy, and the levels of serum progesterone were determined on days 2,8 and 14 of pregnancy in rats treated with or without Ech (Fig. 3). The results revealed that Ech significantly decreased the levels of serum progesterone, compared with the untreated control group, further demonstrating the importance of HIF-1 $\alpha$ in the formation and development of the corpus luteum in vivo. 

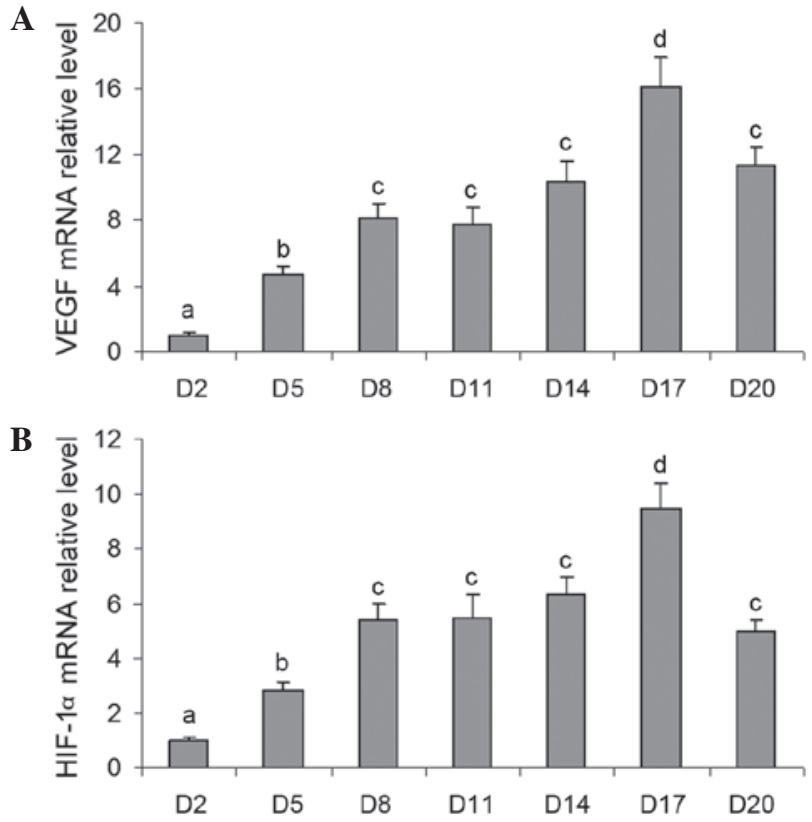

Figure 2. Changes in the mRNA expression of VEGF and HIF-1 $\alpha$ during luteal development in pregnant rats. Relative mRNA levels of (A) VEGF and (B) HIF-1 $\alpha$ were detected using reverse transcription-quantitative polymerase chain reaction analysis on days 2, 5, 8,11, 14, 17 and 20. Data are presented as the mean \pm standard error of the mean. The different letters indicate statistically significant differences in the mean values within and between multiple groups, which was evaluated using a one-way analysis of variance, followed by Tukey's multiple range test. $\mathrm{P}<0.05$ was considered to indicate a statistically significant difference. VEGF, vascular endothelial growth factor; HIF, hypoxia-inducible factor; D, day of pregnancy.

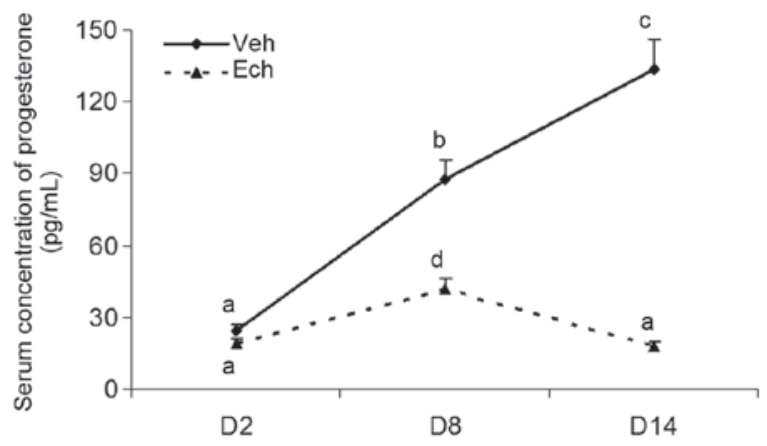

Figure 3. Effects of Ech on luteal development in pregnant rats Adult female rats were mated with males to induce pregnancy. Day 1 of pregnancy was defined as the day when a vaginal plug was recovered. The pregnant rats were intraperitoneally injected with Ech $(1 \mathrm{mg} / \mathrm{kg}$ body weight), a small-molecule inhibitor of HIF-1 $\alpha$, on Day 2 of pregnancy. Animals were sacrificed and trunk blood was collected for progesterone determination on days 2, 8 and 14. The abdomen was opened, and then the ovaries were rapidly excised and chilled in ice-cold $\mathrm{NaCl}(0.154 \mathrm{M})$ with $14.0 \mathrm{uM}$ indomethacin immediately following perfusion for measuring the expression of HIF-1 and VEGF. Each Data are presented as the mean \pm standard error of the mean. The different letters indicate statistically significant differences in the mean values within and between multiple groups, which was evaluated using a one-way analysis of variance, followed by Tukey's multiple range test. $\mathrm{P}<0.05$ was considered to indicate a statistically significant difference. Dimethyl sulfoxide served as the vehicle. VEGF, vascular endothelial growth factor; HIF, hypoxia-inducible factor; Ech, echinomycin; Veh, vehicle; D, day of pregnancy.

Effects of Ech on the mRNA expression levels of VEGF and $H I F-1 \alpha$ during luteal development in pregnant rats. To determine the possible role of HIF-1 $\alpha$ /VEGF signaling during luteal
A

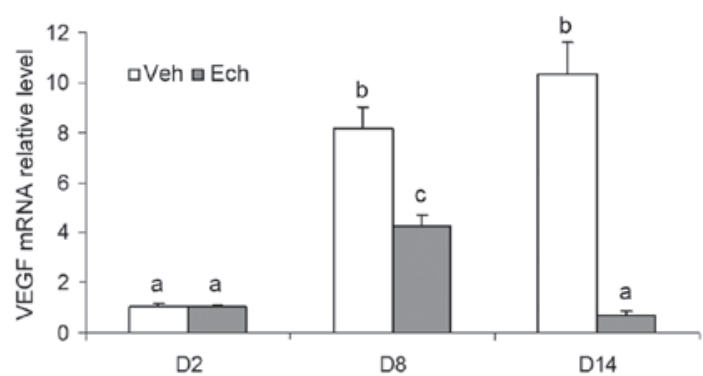

B

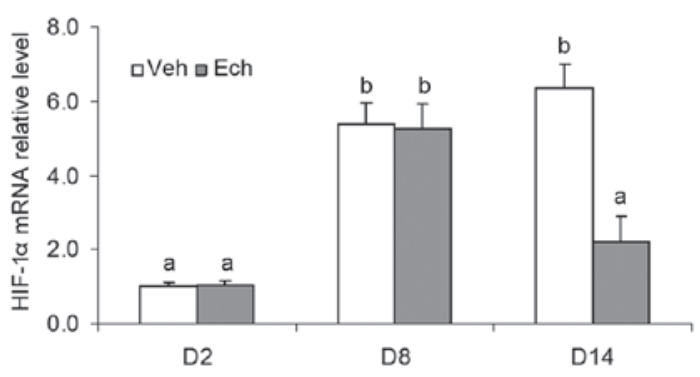

Figure 4. Effects of Ech on the mRNA expression levels of VEGF and HIF-1 $\alpha$ during the luteal development in pregnant rats The relative mRNA levels of (A) VEGF and (B) HIF-1 $\alpha$ were examined using reverse transcription-quantitative polymerase chain reaction analysis on days 2, 8 and 14 . Data are presented as the mean \pm standard error of the mean. The different letters indicate statistically significant differences in the mean values within and between multiple groups, which was evaluated using a one-way analysis of variance, followed by Tukey's multiple range test. $P<0.05$ was considered to indicate a statistically significant difference. Dimethyl sulfoxide served as the vehicle. VEGF, vascular endothelial growth factor; HIF, hypoxia-inducible factor; Ech, echinomycin; Veh, vehicle; D, day of pregnancy.

A

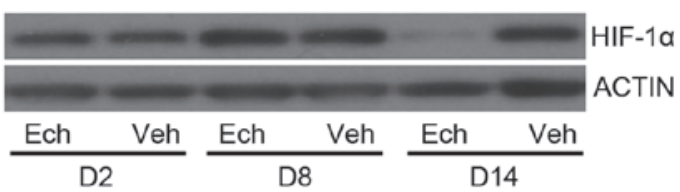

B

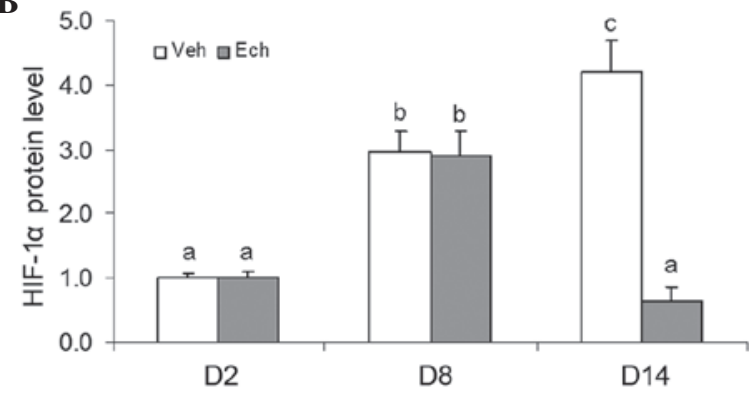

Figure 5. Effects of Ech on the protein expression of HIF-1 $\alpha$ during the luteal development in pregnant rats. (A) Representative western blot analyses of the protein levels of HIF-1 $\alpha$. (B) Summarized intensities of the HIF-1 $\alpha$ blots, normalized to the control. Data are presented as the mean \pm standard error of the mean. The different letters indicate statistically significant differences in the mean values within and between multiple groups, which was evaluated using a one-way analysis of variance, followed by Tukey's multiple range test. $\mathrm{P}<0.05$ was considered to indicate a statistically significant difference. Dimethyl sulfoxide served as the vehicle treatment. HIF, hypoxia-inducible factor; Ech, echinomycin; Veh, vehicle; D, day of pregnancy.

development in vivo, the mRNA expression levels of VEGF and HIF- $1 \alpha$ were also assessed in the ovaries of the pregnant rats treated with or without Ech. The results demonstrated that Ech inhibited the mRNA expression of VEGF in the ovary of 


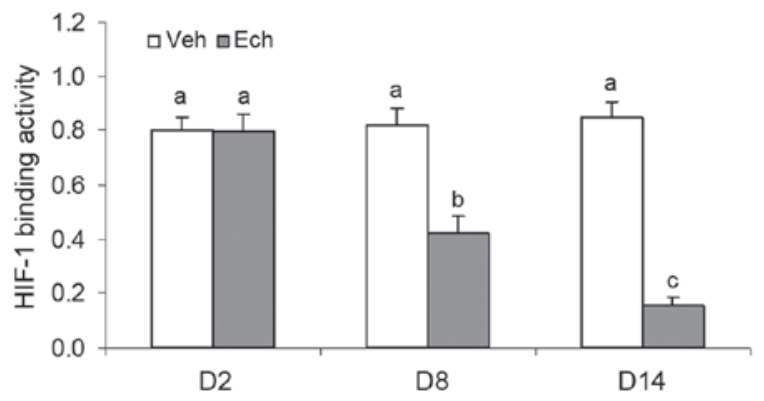

Figure 6. Effects of Ech on HIF-1 binding activity during luteal development in pregnant rats. Data are presented as the mean \pm standard error of the mean. The different letters indicate statistically significant differences in the mean values within and between multiple groups, which was evaluated using a one-way analysis of variance, followed by Tukey's multiple range test. $\mathrm{P}<0.05$ was considered to indicate a statistically significant difference. Dimethyl sulfoxide served as the vehicle treatment. HIF, hypoxia-inducible factor; Ech, echinomycin; Veh, vehicle.

the pregnant rats (Fig. 4A), suggesting that HIF-1 $\alpha$ affected the expression of VEGF during this developmental process. However, no significant changes in the mRNA expression of HIF-1 $\alpha$ were observed in the ovaries following Ech treatment on day 8 of pregnancy, although a marked decrease was observed on day 14 (Fig. 4B). Therefore, the present study investigated the protein expression of HIF- $1 \alpha$.

Effects of Ech on the protein expression of HIF-1 $\alpha$ during luteal development in pregnant rats. The results of examination of the protein expression levels of HIF-1 $\alpha$ in the pregnant ovaries indicated no significant change following Ech treatment on day 8 of pregnancy (Fig. 5), which may be due to Ech being an inhibitor of HIF-1 $\alpha$ activity. A marked decrease in the protein expression of HIF-1 $\alpha$ was observed on day 14 , which may have been caused by luteolysis. Therefore, the binding activity of HIF-1required further analysis.

Effects of Ech on HIF-1 binding activity during luteal development in pregnant rats. To further investigate the regulatory role of HIF- $1 \alpha$ on the mRNA expression of VEGF, the present experiment examined the effects of Ech on HIF-1 binding activity during luteal development in pregnant rats. The results revealed that Ech significantly inhibited the binding activity of HIF-1 (Fig. 6), which contributed to the decrease in the mRNA expression of VEGF in the ovaries of the pregnant rats treated with Ech, and inhibition of the subsequent luteal functions on days 8 and 14 of pregnancy.

\section{Discussion}

The results of the present study demonstrated that HIF-1a and VEGF were expressed in the ovaries, which was similar to serum progesterone secretion in a luteal development-dependent manner in the pregnant rats. This suggested that HIF-1 $\alpha /$ VEGF signaling may have an important regulatory role in corpus luteum formation and development in vivo in mammals.

It is well-known that the corpus luteum is a temporary endocrine structure, which is important in the female reproductive cycle and is formed from a ruptured and ovulated follicle, with rapid angiogenesis, in mammals (1-3,5,9,25). VEGF is considered to be critical in the regulation of normal and abnormal angiogenesis in the ovary $(3,9,13-17,25,30)$, particularly in the newly formed corpus luteum. In primates, VEGF protein is localized in the hormone-producing cells of the corpus luteum, and is highest in the granulosa-derived cells (14-16,30-35). VEGF is fundamental in the physiological angiogenesis and vascularization of the follicular luteinizing granulosa layer during corpus luteum formation $(15,16,30,32)$. Whereas the inhibition of VEGF in vivo during the luteal phase prevents luteal angiogenesis and subsequent progesterone secretion $(2-4,36,37)$, excess VEGF generation during the vascularization of multiple follicles is also considered to cause ovarian hyperstimulation syndrome $(13,38)$. Furthermore, if VEGF is inhibited, the corpus luteum has a rudimentary vascular bed with poor functions (37,39). VEGF is also required for the ongoing function and vasculature maintenance of the mature corpus luteum $(3,4,36)$. These observations are consistent with the those observed in the present study of changes in the mRNA expression levels of VEGF in the luteal development of pregnant rats.

Our previous studies demonstrated that VEGF is transcriptionally activated by an HIF-1 $\alpha$-mediated mechanism in luteal cells cultured in vitro under hypoxia $(9,25)$, which is caused by ovulation of a ruptured follicle with bleeding and immature vasculature in vivo $(5,30)$. However, several reports have also revealed that reproductive hormones, including human chorionic gonadotropim (HCG) are involved in the primary regulation of the expression of VEGF in the ovary. For example, the mRNA expression of VEGF in human luteinized granulosa cells has been observed to increase in a dose- and time-dependent manner by HCG in vitro $(13,38)$. Chronic or acute exposure to HCG directly stimulates the production and secretion of VEGF in monkeys (32) and human luteinized granulosa cells $(2,13,14,38)$. The administration of a gonadotropin-releasing hormone antagonist decreases the mRNA expression of VEGF in the monkey corpus luteum (31). In addition, luteal vascularization and the development of ovarian hyperstimulation syndrome are dependent on luteinizing hormone/HCG stimulation $(13,38)$. Furthermore, in the fully formed, highly vascular corpus luteum, HCG also upregulates the expression of VEGF (2). Therefore, the present study examined changes in the mRNA experssion levels of HIF-1 $\alpha$ during development of the corpus luteum in pregnant rats. The results demonstrated that the expression of HIF-1 $\alpha$ changed in a stage-specific manner and was correlated with the expression of VEGF, suggesting that HIF-1 $\alpha$ may be vital to the VEGF-dependent development of the corpus luteum and its functions in vivo.

HIF-1, a helix-loop-helix transcriptional factor, which consists of HIF- $1 \alpha$ and HIF-1 $\beta$, has been cloned and characterized as a transcriptional activator of several oxygen-sensitive genes, including erythropoietin, heme oxygenases, transferrin and several glycolytic enzymes $(27-29,40)$, whose protein products are important in developmental and physiological processes, including angiogenesis, erythropoiesis, glycolysis, iron transport and cell proliferation/survival $(2,5,11,41-43)$. It has been reported that HIF-1 $\alpha$ protein is inducible by a decrease of $\mathrm{O}_{2}$ concentration in tissue or cells. HIF-1 $\beta$ is not inducible, however, it can be bound to HIF-1 $\alpha$ to form a dimer to activate the transcription of several genes containing 
cis hypoxia-response element in their promoter or enhancer regions $(10,44,45)$. Therefore, the present study treated pregnant rats with a HIF-1 $\alpha$ specific small-molecule inhibitor, Ech, and then examined the levels of gene expression and progesterone secretion. A significant decrease in the level of serum progesterone was found following Ech treatment. Further analysis revealed that the ovarian mRNA level of VEGF was also markedly inhibited, which may contribute to insufficient luteal development and function. However, no significant change in the mRNA expression of HIF-1 $\alpha$ was observed in the ovaries. On subsequent examination of the protein expression of HIF-1 $\alpha$, Ech also had no effect. The following analysis of HIF-1 binding activity suggested that this decrease in the mRNA expression of VEGF may have been caused by the inhibition of Ech on HIF-1 binding activity during luteal development in the pregnant rats. Together, these results suggested that HIF-1 $\alpha$ was involved in luteal function through the VEGF signaling pathway in the ovary of pregnant rats.

In conclusion, the present study demonstrated that changes in the expression of VEGF occurred in a stage-dependent manner during the development of the corpus luteum in the ovary. Further investigation revealed that the change in the expression of VEGF was regulated by HIF-1 $\alpha$ signaling. This HIF-1 $\alpha$-mediated expression of VEGF may be an important mechanism regulating luteal development and function in the mammalian ovary. HIF-1 $\alpha$ antagonism may be useful for the development of novel treatments for fertility control and for certain types of ovarian dysfunction $(11,43,46)$, particularly those conditions characterized by pathological angiogenesis and excessive vascular permeability, including polycystic ovarian syndrome, ovarian hyperstimulation syndrome and ovarian neoplasia.

\section{Acknowledgements}

This study was supported by grants from the National Natural Science Foundation of China (grant. nos. 31101032 and 31271255), the Program for New Century Excellent Talents in University of Ministry of Education of China (grant. no. NCET-120614), the Doctoral Foundation of the Ministry of Education in China (grant. no. 20113503120002) and the Fujian Provincial Science and Technology Projects of the Department of Education (grant. no. JB14041).

\section{References}

1. Young FM, Rodger FE, Illingworth PJ and Fraser HM: Cell proliferation and vascular morphology in the marmoset corpus luteum. Hum Reprod 15: 557-66, 2000.

2. Wulff C, Dickson SE, Duncan WC and Fraser HM: Angiogenesis in the human corpus luteum: Simulated early pregnancy by HCG treatment is associated with both angiogenesis and vessel stabilization. Hum Reprod 16: 2515-2524, 2001.

3. Fraser HM, Bell J, Wilson H, Taylor PD, Morgan K, Abderson RA and Duncan WC: Localization and quantification of cyclic changes in the expression of endocrine gland vascular endothelial growth factor in the human corpus luteum. J Clin Endocrinol Metab 90: 427-434, 2005.

4. Fraser HM and Duncan WC: Vascular morphogenesis in the primate ovary. Angiogenesis 8: 101-116, 2005.

5. Nishimura R and Okuda K: Hypoxia is important for establishing vascularization during corpus luteum formation in cattle. J Reprod Dev 56: 110-116, 2010.
6. Amselgruber WM, Schäfer M and Sinowatz F: Angiogenesis in the bovine corpus luteum: An immunocytochemical and ultrastructural study. Anat Histol Embryol 28: 157-166, 1999.

7. Semenza GL: HIF-1: Mediator of physiological and pathophysiological responses to hypoxia. J Appl Physiol 88: 1474-1480, 2000.

8. Semenza GL: Expression of hypoxia-inducible factor 1: Mechanisms and consequences. Biochem Pharmacol 59: 47-53, 2000.

9. Zhang Z, Yin D and Wang Z: Contribution of hypoxia-inducible factor-1 $\alpha$ to transcriptional regulation of vascular endothelial growth factor in bovine developing luteal cells. Anim Sci J 82: 244-250, 2011.

10. Molitoris KH, Kazi AA and Koos RD: Inhibition of oxygen-induced hypoxia-inducible factor-1alpha degradation unmasks estradiol induction of vascular endothelial growth factor expression in ECC-1 cancer cells in vitro. Endocrinology 150: 5405-5414, 2009.

11. Miyazawa M, Yasuda M, Fujita M, Hirabayashi K, Hirasawa T, Kajiwara H, Muramatsu T, Miyazaki S, Harasawa M, Matsui N, et al: Granulosa cell tumor with activated mTOR-HIF-1alpha-VEGF pathway. J Obstet Gynaecol Res 36: 448-453, 2000.

12. Critchley HO, Osei J,Henderson TA, Boswell L, Sales KJ, Jabbour $\mathrm{HN}$ and Hirani N: Hypoxia-inducible factor-1alpha expression in human endometrium and its regulation by prostaglandin E-series prostanoid receptor 2 (EP2). Endocrinology 147: 744-753, 2006.

13. Neulen J, Yan Z, Raczek S, Weindel K, Keck C, Weich HA, Marmé D and Breckwoldt M: Human chorionic gonadotropin-dependent expression of vascular endothelial growth factor/vascular permeability factor in human granulosa cells: Importance in ovarian hyperstimulation syndrome. J Clin Endocrinol Metab 80: 1967-1971, 1995.

14. Lee A, Christenson LK, Patton PE, Burry KA and Stouffer RL: Vascular endothelial growth factor production by human luteinized granulosa cells in vitro. Hum Reprod 12: 2756-2761, 1997.

15. Shimizu T, Jayawardana BC, Tetsuka M and Miyamoto A: Differential effect of follicle-stimulating hormone and estradiol on expressions of vascular endothelial growth factor (VEGF) 120 , VEGF164 and their receptors in bovine granulosa cells. J Reprod Dev 53: 105-112, 2007.

16. Shimizu T and Miyamoto A: Progesterone induces the expression of vascular endothelial growth factor (VEGF) 120 and Flk-1, its receptor, in bovine granulosa cells. Anim Reprod Sci 102: 228-237, 2007.

17. van den Driesche S, Myers M, Gay E, Thong KJ and Duncan WC: HCG up-regulates hypoxia inducible factor-1 alpha in luteinized granulosa cells: Implications for the hormonal regulation of vascular endothelial growth factor $\mathrm{A}$ in the human corpus luteum. Mol Hum Reprod 14: 455-464, 2008.

18. Khandrika L, Lieberman R, Koul S, Kumar B, Maroni P, Chandhoke R, Meacham RB and Koul HK: Hypoxia-associated p38 mitogen-activated protein kinase-mediated androgen receptor activation and increased HIF-1alpha levels contribute to emergence of an aggressive phenotype in prostate cancer. Oncogene 28: 1248-1260, 2009.

19. Redmer DA and Reynolds LP: Angiogenesis in the ovary. Rev Reprod 1: 182-192, 1996.

20. Fraser HM and Wulff C: Angiogenesis in the primate ovary. Reprod Fertil Dev 13: 557-566, 2001.

21. Fraser HM and Wulff C: Angiogenesis in the corpus luteum. Reprod Biol Endocrinol 1: 88, 2003.

22. Tamanini C and De Ambrogi M: Angiogenesis in developing follicle and corpus luteum. Reprod Domest Anim 39: 206-216 2004

23. Koos RD: Increased expression of vascular endothelial growth/permeability factor in the rat ovary following an ovulatory gonadotropin stimulus: Potential roles in follicle rupture. Biol Reprod 52: 1426-1435, 1995.

24. Nishimura R, Sakumoto R, Tatsukawa Y, Acosta TJ and Okuda $\mathrm{K}$ : Oxygen concentration is an important factor for modulating progesterone synthesis in bovine corpus luteum. Endocrinology 147: 4273-4280, 2006.

25. Zhang Z, Yu D, Yin D and Wang Z: Activation of PI3K/mTOR signaling pathway contributes to induction of vascular endothelial growth factor by hCG in bovine developing luteal cells. Anim Reprod Sci 125: 42-48, 2011.

26. Zhang Z, Pang X, Tang Z, Yin D and Wang Z: Overexpression of hypoxia-inducible factor prolyl hydoxylase-2 attenuates hypoxiainduced vascular endothelial growth factor expression in luteal cells, Mol Med Report 12: 3809-3814, 2015. 
27. Wang Z, Tang L, Zhu Q, Yi F, Zhang F, Li PL and Li N Hypoxia-inducible factor- $1 \alpha$ contributes to the profibrotic action of angiotensin II in renal medullary interstitial cells. Kidney Int 79: 300-310, 2011

28. Wang Z, Zhu Q, Li PL, Dhaduk R, Zhang F, Gehr TW and Li N: Silencing of hypoxia-inducible factor-1 $\alpha$ gene attenuates chronic ischemic renal injury in two-kidney, one-clip rats. Am J Physio Renal Physiol 306: 1236-1242, 2014.

29. Wang Z, Zhu Q, Xia M, Li PL, Hinton SJ and Li N Hypoxia-inducible factor prolyl-hydroxylase 2 senses high-salt intake to increase hypoxia inducible factor lalpha levels in the renal medulla. Hypertension 55: 1129-1136, 2010.

30. Kaczmarek MM, Schams D and Ziecik AJ: Role of vascular endothelial growth factor in ovarian physiology-An overview. Reprod Biol 5: 111-136, 2005.

31. Ravindranath N, Little-Ihrig L, Phillips HS, Ferrara N and Zeleznik AJ: Vascular endothelial growth factor messenger ribonucleic acid expression in the primate ovary. Endocrinology 131: 254-260, 1992

32. Christenson LK and Stouffer RL: Follicle-stimulating hormone and luteinizing hormone/chorionic gonadotropin stimulation of vascular endothelial growth factor production by macaque granulosa cells from pre- and periovulatory follicles. J Clin Endocrinol Metab 82: 2135-2142, 1997.

33. Endo T, Kitajima Y, Nishikawa A, Manase K, Shibuya M and Kudo R: Cyclic changes in expression of mRNA of vascular endothelial growth factor, its receptors Flt-1 and KDR/Flk-1 and Ets-1 in human corpora lutea. Fertil Steril 76: 762-768, 2001.

34. Tesone M, Stouffer RL, Borman SM, Hennebold JD and Molskness TA: Vascular endothelial growth factor (VEGF) production by the monkey corpus luteum during the menstrual cycle: Isoform-selective messenger RNA expression in vivo and hypoxia-regulated protein secretion in vitro. Biol Reprod 73 927-934, 2005

35. Tropea A, Miceli F, Minici F, Tiberi F, Orlando M, Gangale MF, Romani F, Catino S, Mancuso S, Navarra P, et al: Regulation of vascular endothelial growth factor synthesis and release by human luteal cells in vitro. J Clin Endocrinol Metab 91: 2303-2309, 2006.

36. Fraser HM, Wilson H, Wulff C, Rudge JS and Wiegand SJ: Administration of vascular endothelial growth factor Trap during the 'post-angiogenic' period of the luteal phase causes rapid functional luteolysis and selective endothelial cell death in the marmoset. Reproduction 132: 589-600, 2006.
37. Duncan WC, van den Driesche S and Fraser HM: Inhibition of vascular endothelial growth factor in the primate ovary up-regulates hypoxia-inducible factor-1alpha in the follicle and corpus luteum. Endocrinology 149: 3313-3320, 2008.

38. Nastri CO, Ferriani RA, Rocha IA and Martins WP: Ovarian hyperstimulation syndrome: Pathophysiology and prevention. J Assist Reprod Genet 27: 121-128, 2010.

39. Fraser HM and Lunn SF: Angiogenesis and its control in the female reproductive system. Br Med Bull 56: 787-797, 2000. Duncan WC, van den Driesche S and Fraser HM: Inhibition of vascular endothelial growth factor in the primate ovary up-regulates hypoxia-inducible factor-1alpha in the follicle and corpus luteum. Endocrinology 149: 3313-3320, 2008.

40. Wang GL, Jiang BH, Rue EA and Semenza GL: Hypoxia-inducible factor 1 is a basic-helix-loop-helix-PAS heterodimer regulated by cellular O2 tension. Proc Natl Acad Sci USA 92: 5510-5514, 1995.

41. Zhong H, Chiles K, Feldser D, Laughner E, Hanrahan C, Georgescu MM, Simons JW and Semenza GL: Modulation of hypoxia-inducible factor 1alpha expression by the epidermal growth factor/phosphatidylinositol 3-kinase/PTEN/AKT/FRAP pathway in human prostate cancer cells: Implications for tumor angiogenesis and therapeutics. Cancer Res 60: 1541-1545, 2000.

42. Yaba A, Bianchi V, Borini A and Johnson J: A putative mitotic checkpoint dependent on mTOR function controls cell proliferation and survival in ovarian granulosa cells. Reprod Sci 15: 128-138, 2008.

43. Miyazawa M, Yasuda M, Fujita M, Kajiwara H, Hirabayashi K, Takekoshi S, Hirasawa T, Murakami M, Ogane N, Kiguchi K, et al: Therapeutic strategy targeting the mTOR-HIF-1alpha-VEGF pathway in ovarian clear cell adenocarcinoma. Pathol Int 59: 19-27, 2009.

44. Kazi AA, Jones JM and Koos RD: Chromatin immunoprecipitation analysis of gene expression in the rat uterus in vivo: Estrogen-induced recruitment of both estrogen receptor alpha and hypoxia-inducible factor 1 to the vascular endothelial growth factor promoter. Mol Endocrinol 19: 2006-2019, 2005.

45. Kazi AA and Koos RD: Estrogen-induced activation of hypoxia-inducible factor-1alpha, vascular endothelial growth factor expression, and edema in the uterus are mediated by the phosphatidylinositol 3-kinase/Akt pathway. Endocrinology 148: 2363-2374, 2007.

46. Chan DA and Giaccia AJ: PHD2 in tumour angiogenesis. Br J Cancer 103: 1-5, 2010. 